\title{
La tutela cautelar arbitral
}

\section{Natale Amprimo Plá}

¿Hay necesidad de regular el tema de las medidas cautelares en el procedimiento arbitral? La pregunta viene a cuento, pues existe la difundida idea de la brevedad de los procesos arbitrales y, como consecuencia de ello, muchos podrían pensar que aquellas no son necesarias.

La verdad, que no se puede ocultar, es que los procesos arbitrales duran más de lo que se cree y, además, el actor de un proceso arbitral queda sujeto a los mismos riesgos de infructuosidad que soporta el demandante en un proceso judicial ordinario. La experiencia demuestra que la parte que prevé que el laudo no le será favorable utiliza todos los mecanismos a su alcance para dificultar y entorpecer el arbitraje e, incluso, para imposibilitar al máximo la ejecución del laudo.

El debido proceso implica necesariamente una doble vía, la cual, a diferencia de lo que muchos piensan, debe proteger no solo al demandado, sino que alcanza también al demandante y sus derechos, entre los que se encuentra el derecho a conseguir que su pretensión sea atendida y ejecutada eficazmente, y el de ser investido de cautela ante supuestos en que sea previsible que una parte pondrá trabas para obstaculizar la ejecución de lo que se pretende, en caso de que ello fuera amparado.

En ese sentido, el debido proceso es la garantía constitucional que constituye la piedra angular de todo proceso jurisdiccional e involucra, 
entre otros, el derecho a solicitar y, eventualmente, obtener de forma oportuna y efectiva una respuesta jurisdiccional a su pretensión.

Como expresan Derains y Schwartz, "algo vital para el arbitraje es la disponibilidad de medidas cautelares o provisionales efectivas que acompañen al proceso arbitral futuro o en curso. De hecho, en algunos casos, un arbitraje puede ser inútil si no es posible lograr ciertas medidas provisionales rápidamente como, por ejemplo, para asegurar ciertos activos o imponer cierta conducta" (2011: 432-433).

De esta forma, podemos señalar, siguiendo la doctrina especializada, que hay dos razones potentes para permitir medidas cautelares en el arbitraje:

1. La persona que acude al arbitraje para obtener la tutela que le concede el ordenamiento tiene el mismo derecho que el que acude a un procedimiento judicial para obtener esa misma tutela. Resultaría ilógico y perturbador que la tutela cautelar se restringiera únicamente a quienes pretenden la satisfacción de sus pretensiones ante los organismos judiciales estatales.

2. Si no fuera posible adoptar medidas cautelares en apoyo del procedimiento arbitral, nadie mínimamente previsor acudiría al arbitraje, el cual se convertiría en un instrumento absolutamente inútil e impracticable. Como señala Muñoz Sabaté: “De qué sirve otorgar un convenio arbitral, si en caso de un futuro conflicto donde surjan ciertas cautelas previas, ocurre que en el gran almacén donde se expenden dichas cautelas hay apostado un centinela que me dice: 'Usted no tiene derecho a la justicia cautelar porque usted es un ciudadano de segunda'?".

Sin embargo, hay que advertir que en la dación de una medida cautelar hay una suerte de "janismo" o moneda de doble cara, pues una medida cautelar puede servir para la obtención de dos metas claramente contrapuestas: cautelar un interés digno de tutela o entorpecer el ejercicio legítimo de un derecho. Como la lengua de Esopo, la medida cautelar puede servir tanto para lo mejor como para lo peor.

Para graficar mejor lo hasta aquí señalado, explicaré, resumidamente, el famoso caso Himpurna vs. Indonesia. ${ }^{1}$

Himpurna, una sociedad estadounidense, celebra un contrato con la empresa estatal de electricidad de Indonesia, PLN, para explorar, desa-

1 Year Commercial Arbitration, Vol. XXV, 2000. 
rrollar y explotar recursos geotérmicos en dicho país del sudeste asiático y luego venderle a PLN la energía obtenida.

En el contrato intervenía el Gobierno de Indonesia, a través de su Ministerio de Finanzas, a efectos de constituirse como garante de las obligaciones que PLN había asumido frente a Himpurna.

El contrato se desarrollaba debidamente, e Himpurna le vendía electricidad a PLN de manera regular. Pero, con motivo de la crisis asiática, PLN dejó de adquirir la electricidad suministrada por Himpurna, quien la demandó, vía arbitraje, con arreglo al reglamento CNUDMI/Uncitral, conforme a la cláusula arbitral contemplada en el contrato celebrado por ambas partes. La sede sería Yakarta.

El laudo fue favorable a Himpurna, pero PLN se rehusó a pagar. A raíz de ello, con la finalidad de satisfacer su acreencia, Himpurna inició un nuevo proceso arbitral, ahora contra el Gobierno de Indonesia, debido a su deber de garante de las obligaciones del contrato.

Sin embargo, al poco tiempo de la presentación de la segunda demanda arbitral, una empresa estatal indonesa, Pertamina, acude ante los tribunales nacionales de Indonesia, solicitando la suspensión del nuevo arbitraje, y obtiene el dictado de una medida cautelar que ordena dicha suspensión, bajo apercibimiento del pago de un millón de dólares por cada día que se mantenga sin suspenderse el arbitraje, que serán pagados por las partes y los árbitros del tribunal arbitral.

El argumento de Pertamina consistía en invocar una supuesta deuda que el Gobierno de Indonesia le tenía, por lo que solicitaba que, habiendo demandado judicialmente a dicho gobierno, este último no le podía pagar a Himpurna hasta que su caso fuera resuelto, lo que violaba claramente los principios del debido proceso, autonomía de la voluntad y de jurisdicción que posee el arbitraje.

Frente a la arbitrariedad de la medida, el tribunal arbitral decidió mudar su sede de Yakarta a La Haya (Holanda), a efectos de proseguir con el arbitraje, lo que motivó que Indonesia solicitase a un juez de Holanda la suspensión de aquel a través de una medida cautelar, lo que fue rechazado por la judicatura holandesa.

Sin embargo, Indonesia presionó al árbitro que había designado, a efectos de lograr su renuncia, lo que motivó que los dos árbitros restantes emitieran un laudo en el que expusieron de manera exhaustiva los hechos y sus consecuencias jurídicas y concluyeron que podían y debían 
proceder a emitir un laudo definitivo en carácter de tribunal incompleto, lo que hicieron pese a no encontrase presente el tercer árbitro -que era, dicho sea de paso, de nacionalidad indonesa.

Recapitulando: hay que señalar que el fundamento de una medida cautelar radica, principalmente, en el resguardo de bienes jurídicos, o de situaciones que tengan trascendencia jurídica, a fin de que no queden desprotegidos con anterioridad a la sentencia o laudo que se emitirá. En rigor, hay dos razones para esto: 1) proteger la situación de las partes, en espera de la solución del litigio existente, y 2) asegurar la ejecución de la decisión final; todo ello bajo un componente sumamente importante: el tiempo, pues el objetivo es lograr que la decisión que pueda obtenerse mediante el ejercicio e intervención de la acción jurisdiccional o arbitral no llegue demasiado tarde.

En ese sentido, se trata de evitar que el tiempo que transcurre hasta que recae un pronunciamiento firme no suponga la pérdida de la finalidad del proceso. De esta forma, las medidas cautelares pretenden, en definitiva, salvaguardar derechos, siendo, su contenido, preventivo, temporal y variable. Como señala Mallandrich Miret:

Las medidas cautelares constituyen un mecanismo dirigido a mitigar los efectos del tiempo en el proceso, permitiendo asegurar que cuando finalmente se dicte la resolución sobre el fondo del asunto, esta pueda llegar a ser eficaz. Pero, a la vez, las medidas cautelares suponen un daño para la parte contra la que se solicita su otorgamiento. La adopción de una medida cautelar supondrá una injerencia en la esfera jurídica del demandado. A este se le causará un daño, mayor o menor, en función [del] tipo de medida solicitada, pero un daño en definitiva, cuando el ordenamiento jurídico aún no ha reconocido al demandante su derecho para poder causárselo. De hecho, existe la posibilidad [de] que dicho derecho no llegue a reconocerse nunca, ya sea porque se desestime la demanda o porque no llegue a dictarse una resolución sobre el fondo (2010: 113).

¿Cuáles son las características de la medida cautelar? Esta es:

- Instrumental o accesoria, pues el incidente cautelar depende de un proceso principal, que es el que motiva el arbitraje. Es decir, no tiene per se sustantividad propia, justificándose en razón de la presentación de un proceso principal, por lo que no juzga ni prejuzga sobre el derecho del peticionante, limitándose su 
extensión a lo estrictamente indispensable para evitar males ciertos y futuros.

- $\quad$ Variable, pues puede variar y moldearse en beneficio del correcto aseguramiento del interés que se pretende tutelar.

- Provisional, pues únicamente tendrá vigencia durante el trámite del proceso principal. En ese sentido, no puede mantenerse en forma indefinida, pues está condicionada a lo que se resuelva en el fondo del asunto.

- Jurisdiccional, pues la medida es expedida en el marco de un proceso dirigido por un órgano que se encuentra investido con jurisdicción.

En cuanto a la necesidad de permitir la emisión de medidas cautelares, hay que señalar que hoy en día casi todos los reglamentos de los centros de arbitraje, y la mayoría de la legislación comparada, permiten que las partes soliciten ante la justicia ordinaria medidas provisionales o cautelares. Incluso, la mayoría de los reglamentos también autorizan a los árbitros para que emitan medidas cautelares o provisionales.

Sin embargo, cabe anotar que esto no siempre ha sido así, pues hubo épocas en las que no se reconocía la necesidad de permitir la emisión de medidas cautelares. Aún hoy, hay un sector de la doctrina que considera que, teniendo el proceso arbitral su sustento en la voluntad de las partes, y siendo una "jurisdicción de excepción", sus alcances deben interpretarse de manera restrictiva y no extensiva. Así, si la Ley de Arbitraje no prevé la posibilidad de dictar medidas cautelares o si las partes no han otorgado a los árbitros dicha potestad, estos no pueden dictar medidas cautelares (v. g., Jorge Peyrano sostiene: "Si en el acuerdo arbitral no está previsto expresamente el poder cautelar arbitral, consecuentemente, no cuentan con él los árbitros").

Ello también ocurría en el campo legislativo. Así por ejemplo, en Suiza, hasta la entrada en vigencia de la Ley de Derecho Internacional Privado de 1989, solo el Poder Judicial podía emitir medidas cautelares. Incluso es pertinente hacer notar que el propio Reglamento de la CCI - anterior a 1975 - no se refería a una autoridad del tribunal arbitral para emitir medidas cautelares, sino que señalaba que las partes estaban autorizadas para acudir a las cortes "en casos de urgencia, antes o durante el proceso" (Reglamento de 1955, art. 13 (5)). 
Sin embargo, había otro sector de la doctrina que discrepaba con una posición restrictiva y sostenía que si el árbitro tenía competencia para resolver sobre el fondo, ¿por qué negarle la posibilidad de que emita medidas cautelares si estas buscan asegurar la eficiencia de lo que se va a resolver? Además, se sostenía - con razón-que si los árbitros han sido autorizados por las partes para juzgar, ello trae per se la competencia para emitir medidas cautelares.

Por otro lado, hay que señalar que las cortes judiciales, en la mayoría de jurisdicciones, también reconocen hoy la potestad de los árbitros de emitir medidas cautelares, aun cuando existe una serie de casos en Estados Unidos que se apartan de dicha tendencia, pues en ellos se ha sostenido que, bajo la Convención de Nueva York, las cortes no pueden ordenar embargos antes de emitir un laudo arbitral. ${ }^{2}$

Esto último motivó que, a fin de evitar dudas, se modificara la Ley Modelo de Uncitral en 2006 y se incorporaran los artículos 17 H y 17 I.

El artículo 17 I se refiere a los motivos para denegar el reconocimiento o la ejecución, mientras que el artículo 17 H señala:

Artículo 17 H: Reconocimiento y ejecución

1. Toda medida cautelar ordenada por un tribunal arbitral se reconocerá como vinculante $\mathrm{y}$, salvo que el tribunal disponga otra cosa, será ejecutada al ser solicitada tal ejecución ante el tribunal competente, cualquiera que sea el Estado en donde haya sido ordenada, y a reserva de lo dispuesto en el artículo 17 I.

2. La parte que solicite o haya obtenido el reconocimiento o la ejecución de una medida cautelar informará sin demora al tribunal de toda revocación, suspensión o modificación que se ordene de dicha medida.

3. El tribunal ante el que sea solicitado el reconocimiento o la ejecución de una medida cautelar podrá, si lo considera oportuno, exigir de la parte solicitante que preste una garantía adecuada, cuando el tribunal arbitral no se haya pronunciado aún sobre tal garantía o cuando esa garantía sea necesaria para proteger los derechos de terceros.

2 El artículo III de la Convención de Nueva York señala: "Cada uno de los Estados contratantes reconocerá la autoridad de la sentencia arbitral y concederá su ejecución de conformidad con las normas de procedimiento vigentes en el territorio donde la sentencia sea invocada $[\ldots]^{\prime \prime}$. 
A su vez, la Ley de Arbitraje peruana, Decreto Legislativo 1071, dispone en el inciso 9 del artículo 47: “En el arbitraje internacional, las partes durante el proceso de las actuaciones pueden también solicitar a la autoridad judicial competente, previa autorización del tribunal arbitral, la adopción de medidas cautelares".

Ahora bien, ¿quién es competente para dictar medidas cautelares?

\section{a) El Poder Judicial}

La Ley Modelo Uncitral (en su versión corregida de 2006) señala, en su artículo 9: "No será incompatible con un acuerdo de arbitraje que una parte, ya sea con anterioridad a las actuaciones arbitrales o durante su transcurso, solicite de un tribunal la adopción de medidas cautelares ni que el tribunal conceda esas medidas".

El Reglamento de Arbitraje de Uncitral (versión 2010) indica, en el inciso 9 del artículo 26: "La adopción de medidas cautelares dirigida a una autoridad judicial por cualquiera de las partes no será tenida por incompatible con el acuerdo de arbitraje ni como una renuncia a ese acuerdo".

El Reglamento de Arbitraje de la CCI (versión 2012) dispone, en el inciso 2 del artículo 28:

Antes de la entrega del expediente al tribunal arbitral, y en circunstancias apropiadas aun después, las partes podrán solicitar a cualquier autoridad judicial competente la adopción de medidas provisionales o cautelares. La solicitud que una parte haga a una autoridad judicial con el fin de obtener tales medidas o la ejecución de medidas similares ordenadas por un tribunal arbitral no contraviene al acuerdo de arbitraje ni constituye una renuncia a este y no afecta los poderes del tribunal arbitral al respecto. Dicha solicitud, así como cualquier medida adoptada por la autoridad judicial, debe ser notificada sin dilación a la Secretaría. Esta última informará de ello al tribunal arbitral.

El Reglamento de Arbitraje del Centro Internacional de Arreglo de Diferencias relativas a Inversiones (Ciadi) precisa, en el inciso 5 de la regla 39: "Nada en esta regla impedirá que las partes, siempre que lo hayan estipulado en el convenio que registre su consentimiento, soliciten a cualquier autoridad judicial o de otra naturaleza que dicte medi- 
das provisionales, antes de la iniciación del procedimiento o durante la sustanciación del procedimiento, para la preservación de sus respectivos derechos e intereses".

La Ley de Arbitraje peruana, Decreto Legislativo 1071, señala, en los incisos 4 y 5 del artículo 47:

4. Las medidas cautelares solicitadas antes de la constitución del tribunal arbitral no son incompatibles con el arbitraje ni consideradas como una renuncia a él. Ejecutada la medida, la parte beneficiada deberá iniciar el arbitraje dentro de los diez (10) días siguientes, si no lo hubiere hecho con anterioridad. Si no lo hace dentro de ese plazo o habiendo cumplido con hacerlo, no se constituye el tribunal arbitral dentro de los noventa (90) días de dictada la medida, esta caduca de pleno derecho.

5. Constituido el tribunal arbitral, cualquiera de las partes puede informar a la autoridad judicial de este hecho y pedir la remisión al tribunal del expediente del proceso cautelar. La autoridad judicial está obligada, bajo responsabilidad, a remitirla en el estado en que se encuentre, sin perjuicio de que cualquiera de las partes pueda presentar al tribunal arbitral copia de los actuados del proceso cautelar. La demora de la autoridad judicial en la remisión, no impide al tribunal arbitral pronunciarse sobre la medida cautelar solicitada, dictada o impugnada. En este último caso, el tribunal arbitral tramitará la apelación interpuesta bajo los términos de una reconsideración contra la medida cautelar.

En cuanto a la Ley de Arbitraje peruana, cabe preguntarse si, una vez constituido el tribunal arbitral, el Poder Judicial puede continuar dictando medidas cautelares. Al respecto, cabe indicar que la respuesta no es única, pues depende del tipo de arbitraje en el que nos encontremos. Así:

- $\quad$ Si estamos ante un arbitraje internacional (artículo 5), la respuesta es afirmativa, pero previa autorización del tribunal arbitral, conforme lo prevé el inciso 9 del artículo 47, que dispone: "En el arbitraje internacional, las partes durante el proceso de las actuaciones pueden también solicitar a la autoridad judicial competente, previa autorización del tribunal arbitral, la adopción de medidas cautelares". 
- Si estamos ante un arbitraje nacional o doméstico, la respuesta es negativa, pues el inciso 1 del artículo 3 señala: "En los asuntos que se rijan por este Decreto Legislativo no intervendrá la autoridad judicial, salvo en los casos en que esta norma así lo disponga".

Otro tema importante respecto a las medidas cautelares otorgadas en el Poder Judicial es el referido a qué ley aplica el juez cuando le solicitan la medida cautelar. ¿La Ley de Arbitraje peruana o el Código Procesal Civil? ¿Se otorga inaudita parte o ex parte?

Hay quien sostiene que el juez debe exigir el cumplimiento de las condiciones que contempla el Código Procesal Civil y actuar conforme lo dispone esta normativa (por ejemplo, se debe ofrecer contracautela - art. 610- y el pedido es concedido o rechazado sin conocimiento de la parte afectada - art. 637-). Sin embargo, consideramos que ello no es correcto, pues la Ley de Arbitraje peruana no contempla requisitos (solo habla de la contracautela en términos potestativos -inc. 1 del art. 47-) y el procedimiento ordinario contempla que, antes de resolver, se ponga en conocimiento la solicitud de medida cautelar a la parte contraria (inc. 3 del art. 47). En ese sentido, consideramos que se debe seguir lo que indica la Ley de Arbitraje peruana, habida cuenta de que la décima disposición final del Decreto Legislativo 1071 contempla el principio de prevalencia cuando señala: "Las disposiciones procesales de esta norma respecto de cualquier actuación judicial prevalecen sobre las normas del Código Procesal Civil".

\section{b) El propio tribunal arbitral}

La Ley Modelo Uncitral (en su versión corregida de 2006) señala, en su artículo 17:

1. Salvo acuerdo en contrario de las partes, el tribunal arbitral podrá, a instancia de una de ellas, otorgar medidas cautelares.

2. Por medida cautelar se entenderá toda medida temporal, otorgada en forma o no de laudo, por la que, en cualquier momento previo a la emisión del laudo por el que se dirima definitivamente la controversia, el tribunal arbitral ordene a una de las partes que:

a) mantenga o restablezca el statu quo en espera de que se dirima la controversia; 
b) adopte medidas para impedir algún daño actual o inminente o el menoscabo del procedimiento arbitral, o que se tengan que llevar a cabo ciertos actos que probablemente ocasionarían dicho daño o menoscabo al procedimiento arbitral;

c) proporcione algún medio para preservar bienes que permitan ejecutar todo laudo subsiguiente; o

d)Preserve elementos de prueba que pudieran ser relevantes y pertinentes para resolver la controversia.

El Reglamento de Arbitraje de la CCI (versión 2012) dispone, en el inciso 1 del artículo 28:

Salvo acuerdo de las partes en contrario, el tribunal arbitral podrá, desde el momento en que se le haya entregado el expediente, ordenar, a solicitud de parte, cualquiera medidas cautelares o provisionales que considere apropiadas. El tribunal arbitral podrá subordinar dichas medidas al otorgamiento de una garantía adecuada por la parte que las solicite. Las medidas mencionadas deberán ser adoptadas mediante orden motivada o laudo, según el tribunal lo estime conveniente.

Incluso, el mismo Reglamento de Arbitraje de la CCI (versión 2012) contempla la posibilidad de que un "árbitro de emergencia" otorgue una medida cautelar si no se puede esperar hasta la constitución del tribunal arbitral. Así, los incisos 1 al 3 del artículo 29 señalan:

\section{Árbitro de emergencia}

1. La parte que requiera medidas cautelares o provisionales urgentes que no pueden esperar hasta la constitución del tribunal arbitral ("Medidas de Emergencia") podrá solicitar tales medidas según las reglas de árbitro de emergencia previstas en el apéndice V. Tal solicitud será aceptada por la Corte solo si es recibida por la Secretaría antes de la entrega del expediente al tribunal arbitral de conformidad con el artículo 16 e independientemente de si la parte que la hace ha presentado ya su solicitud de arbitraje.

2. La decisión del árbitro de emergencia deberá adoptar la fórmula de una orden. Las partes se comprometen a cumplir con cualquier orden dictada por el árbitro de emergencia. 
3. La orden del árbitro de emergencia no será vinculante para el tribunal arbitral en relación con cualquier cuestión, tema o disputa decidida en la orden. El tribunal arbitral puede modificar, dejar sin efecto o anular la orden o cualquier modificación de la misma hecha por el árbitro de emergencia.

El Reglamento de la Corte Internacional de Arbitraje de Londres sanciona, en el artículo 25:

Artículo 25: Medidas cautelares y conservatorias

25.1 A menos que las partes pacten lo contrario por escrito, el tribunal arbitral tendrá la facultad, a solicitud de cualquiera de las partes, de:

(a) ordenar a cualquier demandado o reconvenido que preste garantía por todo o parte de la cantidad en disputa a través de la constitución de un depósito o garantía bancaria o de cualquier otra manera, en los términos que el tribunal arbitral considere adecuado a tal fin. Dichos términos podrán incluir la constitución de una contracautela que el demandante o reconviniente deberá prestar en la forma que el tribunal considere adecuada y cuyo objeto será el de garantizar cualquier coste o pérdida en la que pueda incurrir el demandado al proporcionar la garantía requerida. El tribunal arbitral podrá cuantificar los costes y pérdidas cubiertos por la contracautela en uno o varios pronunciamientos.

(b) ordenar la conservación, almacenamiento, venta o enajenación de cosas o propiedades que se encuentren en poder de cualquiera de las partes y que guarden relación con el litigio objeto de arbitraje, $\mathrm{y}$

(c) ordenar de forma provisional, con sujeción a lo que se acuerde de forma definitiva en el laudo, cualquier otra medida que el tribunal pueda acordar en un laudo, incluyendo la adopción de una orden provisional de pago o la disposición de una propiedad de cualquiera de las partes.

25.2 El tribunal arbitral podrá, a instancia de parte, ordenar al demandante o reconviniente que preste garantía a través de la constitución de un depósito o garantía bancaria o de cualquier otro 
medio que el tribunal arbitral considere adecuado a tal fin, para cubrir los gastos legales $u$ otros gastos en los que el demandado o reconvenido pueda incurrir. El tribunal arbitral podrá cuantificar los gastos a satisfacer con esa garantía en uno o varios pronunciamientos. En caso de que el demandante o reconviniente no prestara la garantía requerida, el tribunal arbitral podrá paralizar la demanda o reconvención o rechazarla en su laudo.

25.3 El poder concedido al tribunal arbitral en el artículo 25.1 se establece sin detrimento del derecho de cualquiera de las partes de solicitar ante cualquier tribunal estatal $\mathrm{u}$ otra autoridad judicial la adopción de medidas cautelares con anterioridad a la formación del tribunal arbitral y, en casos excepcionales, incluso con posterioridad a la misma. Cualquier solicitud de adopción de medidas cautelares realizada con posterioridad a la formación del tribunal arbitral deberá ser comunicada por el solicitante al tribunal y al resto de las partes a la mayor brevedad posible. Sin embargo, el acuerdo de sometimiento del arbitraje a las presentes reglas implica la renuncia de las partes a solicitar a un tribunal estatal o a cualquier otra autoridad judicial una garantía para asegurar los gastos legales o los otros gastos a los que se refiere el artículo 25.2.

El Reglamento de Arbitraje de la Asociación Americana de Arbitraje (AAA) señala, en el artículo 21:

Artículo 21.- Medidas cautelares de protección

1. El tribunal, previa solicitud de cualquier parte, podrá adoptar cualquier medida cautelar que estime necesaria, incluyendo medidas sumarias y medidas de protección y conservación de la propiedad.

2. Estas medidas cautelares podrán adoptar la forma de laudo provisional, pudiendo el tribunal requerir garantía de los costes derivados de tales medidas.

3. Las medidas cautelares solicitadas por una parte ante la autoridad judicial no se considerarán incompatibles con el acuerdo de arbitraje ni una renuncia al derecho al arbitraje.

4. El tribunal podrá distribuir los costes asociados a las solicitudes de medidas cautelares en un laudo provisional o en el laudo definitivo. 
El Reglamento de Arbitraje de la Organización Mundial de la Propiedad Intelectual (WIPO) dispone, en el artículo 46:

Artículo 46.- Medidas cautelares de protección: Garantías por reclamaciones y gastos.

a) Siempre que el convenio arbitral prevea la aplicación de las reglas de medidas cautelares de emergencia de la WIPO conjuntamente con las reglas ordinarias de arbitraje de la WIPO, las normas contenidas en el anexo de tales reglas también formarán parte del convenio arbitral.

b) El tribunal, a solicitud de parte, podrá dictar órdenes provisionales y adoptar las medidas cautelares que considerare necesarias, inclusive medidas sumarias y medidas para la conservación de los bienes relacionados con el asunto objeto de disputa, así como ordenar que los bienes se depositen en manos de un tercero o que se vendan los bienes perecederos. El tribunal podrá condicionar la concesión de tales medidas a la prestación de una garantía adecuada por la parte solicitante.

c) El tribunal, a solicitud de parte, podrá, si considera que se dan circunstancias excepcionales que lo requieran, ordenar a la contraparte prestar garantía en la forma que determine el tribunal respecto a la demanda o la reconvención, así como con respecto a los costes a los que se refiere el articulo 72 .

d) Las medidas y órdenes contempladas en este artículo podrán adoptar la forma de laudo provisional.

e) la solicitud de adopción de medidas cautelares, o de una garantía respecto a la demanda o reconvención, o para la ejecución de cualesquiera medidas u órdenes acordadas por el tribunal arbitral, dirigidas a la autoridad judicial por cualquiera de las partes, no se considerará incompatible con el convenio de arbitraje ni se entenderá como una renuncia a ese convenio.

El Reglamento de Arbitraje del Centro Internacional de Arreglo de Diferencias relativas a Inversiones (Ciadi) precisa, en los artículos 47 y 39:

Artículo 47.- Salvo acuerdo contrario de las partes, el tribunal, si considera que las circunstancias así lo requieren, podrá recomendar la adopción de aquellas medidas provisionales que considere necesarias para salvaguardar los respectivos derechos de las partes. 
Artículo 39.-

1. En cualquier etapa del procedimiento, cualquiera de las partes puede solicitar que el tribunal recomiende la adopción de medidas provisionales para la salvaguarda de sus derechos. La solicitud deberá especificar los derechos que se salvaguardarán, las medidas cuya recomendación se pide, y las circunstancias que hacen necesaria la dictación de tales medidas.

[...].

3. El tribunal también podrá recomendar de oficio la adopción de medidas provisionales, o recomendar medidas distintas de las indicadas en la petición. Podrá modificar o revocar sus recomendaciones en cualquier momento.

4. El tribunal sólo recomendará medidas provisionales, o modificará o revocará sus recomendaciones, después de dar a cada parte una oportunidad para que haga presente sus observaciones.

La Ley de Arbitraje peruana, Decreto Legislativo 1071, preceptúa, en el inciso 1 del artículo 47: "Una vez constituido, el tribunal arbitral, a petición de cualquiera de las partes, podrá adoptar las medidas cautelares que considere necesarias para garantizar la eficacia del laudo, pudiendo exigir las garantías que estime convenientes para asegurar el resarcimiento de los daños y perjuicios que pueda ocasionar la medida".

Hay que señalar que la Ley de Arbitraje peruana solo habla de medidas cautelares, y dentro de dicho concepto engloba a todo tipo de medidas. Sin embargo, muchos reglamentos se refieren a medidas cautelares y a medidas $\mathrm{u}$ órdenes provisionales. ¿Hay diferencia?

En sentido "técnico procesal":

- "Medidas cautelares": Son aquellas que van dirigidas a asegurar la efectividad de la resolución que un día se dicte; es decir, a garantizar la eficacia del futuro laudo.

- "Medidas de aseguramiento de prueba": Son aquellas tendentes a asegurar la pervivencia de alguna fuente de prueba.

- "Medidas provisionales": Son resoluciones adoptadas por el tribunal para mantener la situación existente durante el procedimiento, hasta que se dicte una resolución definitiva poniendo fin al litigio. 
A este respecto, la Ley Modelo Uncitral diferencia entre medidas cautelares y órdenes provisionales. Así, la Ley Modelo, en su versión corregida 2006, hace una diferencia entre medidas cautelares y órdenes provisionales. Respecto a estas últimas, consigna:

Artículo 17B.- Petición de una orden preliminar y condiciones para su otorgamiento.

1) Salvo acuerdo en contrario de las partes, toda parte, sin dar aviso a ninguna otra parte, podrá solicitar una medida cautelar y pedir una orden preliminar del tribunal arbitral por la que se ordena a alguna parte que no frustre la finalidad de la medida cautelar solicitada.

2) El tribunal podrá emitir una orden preliminar siempre que considere que la notificación previa de la solicitud de una medida cautelar a la parte contra la cual esa medida vaya dirigida entraña el riesgo de que se frustre la medida solicitada

$[\ldots]$.

Artículo 17C.- Régimen específico de las órdenes preliminares.

Inmediatamente después de haberse pronunciado sobre la procedencia de una petición de orden preliminar, el tribunal arbitral notificará a todas las partes la solicitud presentada de una medida cautelar, la petición de una medida preliminar, la propia orden preliminar, en caso de haberse otorgado, así como todas las comunicaciones al respecto, incluida la constancia del contenido de toda comunicación verbal, entre cualquiera de las partes y el tribunal arbitral en relación con ello.

$[\ldots]$.

4) Toda orden preliminar expirará a los veinte días contados a partir de la fecha en que el tribunal arbitral la haya emitido. No obstante, el tribunal arbitral podrá otorgar una medida cautelar por la que ratifique o modifique la orden preliminar una vez que la parte contra la que se dirigió la orden preliminar haya sido notificada y haya tenido la oportunidad de hacer valer sus derechos.

5) Una orden preliminar será vinculante para las partes, pero no será de por sí objeto de ejecución judicial. Dicha orden no constituirá un laudo. 
Un tema interesante en las medidas cautelares es el relativo a si se puede pactar la renuncia a solicitarlas. Como hemos visto, tanto la Ley Modelo, como el Reglamento CCI, establecen que la potestad del tribunal arbitral para emitir medidas cautelares está condicionada a, en primer término, la voluntad de las partes. Igual ocurre en la Ley de Arbitraje española (art. 23). Es decir, admiten que las partes - ya sea en el convenio arbitral, antes o durante el arbitraje - puedan pactar que renuncian a la tutela cautelar. ¿Ello les impide solicitar una medida cautelar?

El Tribunal Constitucional español, en la sentencia 218/1994, del 18 de julio de 1994, ha recordado que "la tutela judicial no es tal sin medidas cautelares adecuadas que aseguren el efectivo cumplimiento de la resolución definitiva que recaiga en el proceso", por lo que el legislador no puede quitar de manera absoluta la posibilidad de eliminar medidas cautelares dirigidas a asegurar la efectividad de la sentencia estimatoria, "pues con ello se vendría a privar a los justiciables de una garantía que [...] se configura como contenido del derecho a la tutela judicial efectiva" (STC 14/1982, fundamento jurídico 3). En consecuencia, en España, si las partes limitaron a los árbitros la competencia para emitir medidas cautelares, aquellas pueden recurrir al Poder Judicial a solicitar su obtención.

Opinamos que en el Perú no se puede limitar dicha competencia a los árbitros, pues ello implicaría desguarnecer el derecho a la tutela efectiva; en ese sentido, para garantizar este derecho, se debe ofrecer a las partes una vía cautelar. Aceptar que las partes pueden renunciar a priori a la posibilidad de solicitar cualquier tipo de medida cautelar afecta el derecho a la tutela efectiva y puede situar, a la parte que solicita tutela a los árbitros, en una posición de indefensión.

En cuanto a los requisitos para la concesión de medidas arbitrales, hay que señalar que la Ley de Arbitraje peruana, al igual que la Ley de Arbitraje española, no regula específicamente los presupuestos de las medidas cautelares. El artículo 47 sólo prevé en forma expresa la posibilidad de que el árbitro exija "las garantías que estime conveniente para asegurar el resarcimiento de los daños y perjuicios que pueda ocasionar la ejecución de la medida".

La Ley de Arbitraje peruana no regula los demás presupuestos clásicos concernientes a la necesidad de que exista un fumus boni iuris y que concurra periculum in mora. Sin embargo, la no regulación expresa no debe interpretarse directamente en el sentido de que los árbitros pueden 
adoptar medidas cautelares prescindiendo totalmente de comprobar la concurrencia de estos presupuestos. El inciso 3 del artículo 34 del Decreto Legislativo 1071 señala cómo proceder en caso de vacío normativo: "Si no existe norma aplicable en este decreto legislativo, el tribunal podrá recurrir, según su criterio, a los principios arbitrales, así como a los usos y costumbres en materia arbitral".

Sobre esto último, en la Ley Modelo Uncitral se exigen dos requisitos: peligro en la demora y verificación del derecho, salvo para el caso de la preservación de pruebas. Así, señala:

Artículo 17. Facultad del tribunal arbitral para otorgar medidas cautelares

1) Salvo acuerdo en contrario de las partes, el tribunal podrá, a instancia de una de ellas, otorgar medidas cautelares.

2) Por medida cautelar se entenderá toda medida temporal, otorgada en forma o no de laudo, por la que, en cualquier momento previo a la emisión del laudo por el que se dirima definitivamente la controversia, el tribunal arbitral ordene a una de las partes que:

a) mantenga o restablezca el statu quo en espera de que se dirima la controversia;

b) adopte medidas para impedir algún daño actual o inminente o el menoscabo del procedimiento arbitral, o que se abstenga de llevar a cabo ciertos actos que probablemente ocasionarían dicho daño o menoscabo al procedimiento arbitral;

c) proporcione algún medio para preservar bienes que permitan ejecutar todo laudo subsiguiente; o

d) preserve elementos de prueba que pudieran ser relevantes y pertinentes para resolver la controversia.

Artículo 17 A. Condiciones para el otorgamiento de medidas cautelares

1) El solicitante de alguna medida cautelar prevista en los apartados a), b) o c) del párrafo 2) del artículo 17 deberá convencer al tribunal arbitral de que:

a) de no otorgarse la medida cautelar es probable que se produzca algún daño, no resarcible adecuadamente mediante una 
indemnización, que sea notablemente más grave que el que pueda sufrir la parte afectada por la medida, caso de ser ésta otorgada; y

b) existe una posibilidad razonable de que su demanda sobre el fondo del litigio prospere. La determinación del tribunal arbitral respecto de dicha posibilidad no prejuzgará en modo alguno toda determinación subsiguiente a que pueda llegar dicho tribunal.

2) En lo que respecta a toda solicitud de una medida cautelar presentada con arreglo al apartado d) del párrafo 2) del artículo 17, los requisitos enunciados en los apartados a) y b) del párrafo 1) del presente artículo sólo serán aplicables en la medida en que el tribunal arbitral lo estime oportuno.

Por su parte, la Ley de Arbitraje peruana establece, en sus artículos 47 y 48 :

Artículo 47.- Medidas cautelares

1. Una vez constituido, el tribunal arbitral, a petición de cualquiera de las partes, podrá adoptar las medidas cautelares que considere necesarias para garantizar la eficacia del laudo, pudiendo exigir las garantías que estime conveniente para asegurar el resarcimiento de los daños y perjuicios que pueda ocasionar la ejecución de la medida.

2. Por medida cautelar se entenderá toda medida temporal, contenida en una decisión que tenga o no forma de laudo, por la que, en cualquier momento previo a la emisión del laudo que resuelva definitivamente la controversia, el tribunal arbitral ordena a una de las partes:

a. Que mantenga o restablezca el statu quo en espera de que se resuelva la controversia;

b. Que adopte medidas para impedir algún daño actual o inminente o el menoscabo del proceso arbitral, o que se abstenga de llevar a cabo ciertos actos que probablemente ocasionarían dicho daño o menoscabo al proceso arbitral;

c. Que proporcione algún medio para preservar bienes que permitan ejecutar el laudo subsiguiente; o

d. Que preserve elementos de prueba que pudieran ser relevantes y pertinentes para resolver la controversia. 
3. El tribunal arbitral, antes de resolver, pondrá en conocimiento la solicitud a la otra parte. Sin embargo, podrá dictar una medida cautelar sin necesidad de poner en conocimiento a la otra parte, cuando la parte solicitante justifique la necesidad de no hacerlo para garantizar que la eficacia de la medida no se frustre. Ejecutada la medida, podrá formularse reconsideración contra la decisión.

4. Las medidas cautelares solicitadas a una autoridad judicial antes de la constitución del tribunal arbitral no son incompatibles con el arbitraje ni consideradas como una renuncia a él. Ejecutada la medida, la parte beneficiada deberá iniciar el arbitraje dentro de los diez (10) días siguientes, si no lo hubiere hecho con anterioridad. Si no lo hace dentro de este plazo o habiendo cumplido con hacerlo, no se constituye el tribunal arbitral dentro de los noventa (90) días de dictada la medida, esta caduca de pleno derecho.

5. Constituido el tribunal arbitral, cualquiera de las partes puede informar a la autoridad judicial de este hecho y pedir la remisión al tribunal del expediente del proceso cautelar. La autoridad judicial está obligada, bajo responsabilidad, a remitirlo en el estado en que se encuentre, sin perjuicio de que cualquiera de las partes pueda presentar al tribunal arbitral copia de los actuados del proceso cautelar. La demora de la autoridad judicial en la remisión, no impide al tribunal arbitral pronunciarse sobre la medida cautelar solicitada, dictada o impugnada. En este último caso, el tribunal arbitral tramitará la apelación interpuesta bajo los términos de una reconsideración contra la medida cautelar.

6. El tribunal arbitral está facultado para modificar, sustituir y dejar sin efecto las medidas cautelares que haya dictado así como las medidas cautelares dictadas por una autoridad judicial, incluso cuando se trate de decisiones judiciales firmes. Esta decisión podrá ser adoptada por el tribunal arbitral, ya sea a iniciativa de alguna de las partes o, en circunstancias excepcionales, por iniciativa propia, previa notificación a ellas.

7. El tribunal arbitral podrá exigir a cualquiera de las partes que dé a conocer, sin demora, todo cambio importante que se produzca en las circunstancias que motivaron que la medida se solicitara o dictara.

8. El solicitante de una medida cautelar será responsable de los costos y de los daños y perjuicios que dicha medida ocasione a algu- 
na de las partes, siempre que el tribunal arbitral determine ulteriormente que, en las circunstancias del caso, no debería haberse otorgado la medida. En ese caso, el tribunal arbitral podrá condenar al solicitante, en cualquier momento de las actuaciones, al pago de los costos y de los daños y perjuicios.

9. En el arbitraje internacional, las partes durante el transcurso de las actuaciones pueden también solicitar a la autoridad judicial competente, previa autorización del tribunal arbitral, la adopción de las medidas cautelares que estimen convenientes.

Artículo 48.- Ejecución de medidas cautelares dictadas por el tribunal arbitral

1. El tribunal arbitral está facultado para ejecutar, a pedido de parte, sus medidas cautelares, salvo que, a su sola discreción, considere necesario o conveniente requerir la asistencia de la fuerza pública.

2. En los casos de incumplimiento de la medida cautelar o cuando se requiera de ejecución judicial, la parte interesada recurrirá a la autoridad judicial competente, quien por el solo mérito de las copias del documento que acredite la existencia del arbitraje y de la decisión cautelar, procederá a ejecutar la medida sin admitir recursos ni oposición alguna.

3. La autoridad judicial no tiene competencia para interpretar el contenido ni los alcances de la medida cautelar. Cualquier solicitud de aclaración o precisión sobre los mismos o sobre la ejecución cautelar, será solicitada por la autoridad judicial o por las partes al tribunal arbitral. Ejecutada la medida, la autoridad judicial informará al tribunal arbitral y remitirá copia certificada de los actuados.

4. Toda medida cautelar ordenada por un tribunal arbitral cuyo lugar se halle fuera del territorio peruano podrá ser reconocida y ejecutada en el territorio nacional, siendo de aplicación lo dispuesto en los artículos 75, 76 y 77, con las siguientes particularidades:

a. Se podrá denegar la solicitud de reconocimiento, solo por las causales a, b, c y d del numeral 2 del artículo 75 o cuando no se dé cumplimiento a lo dispuesto en el inciso $\mathrm{d}$ de este numeral.

b. La parte que pida el reconocimiento de la medida cautelar deberá presentar el original o copia de la decisión del tribunal arbitral, debiendo observar lo previsto en el artículo 9. 
c. Los plazos dispuestos en los numerales 2 y 3 del artículo 76 serán de diez (10) días.

d. La autoridad judicial podrá exigir a la parte solicitante que preste una garantía adecuada, cuando el tribunal arbitral no se haya pronunciado aún sobre tal garantía o cuando esa garantía sea necesaria para proteger los derechos de terceros. Si no se da cumplimiento, la autoridad judicial podrá rechazar la solicitud de reconocimiento.

e. La autoridad judicial que conoce de la ejecución de la medida cautelar podrá rechazar la solicitud, cuando la medida cautelar sea incompatible con sus facultades, a menos que decida reformular la medida para ajustarla a sus propias facultades y procedimientos a efectos de poderla ejecutar, sin modificar su contenido ni desnaturalizarla.

\section{Bibliografía}

Derains, Yves y Eric A. Schwartz (2011). Una guía al reglamento de arbitraje de la Cámara de Comercio Internacional. Bogotá: Universidad del Rosario.

Mallandrich Miret, Nuria (2010). Medidas cautelares y arbitraje. Barcelona: Atelier. 